\title{
INTERNAL CONTROL AND ITS REFLECTION IN ENHANCING THE ADMINISTRATIVE DECISION-MAKING PROCESS IN KIRKUK WATER DIRECTORATE
}

\author{
Tareq Abdul Sattar Mohammed \\ Supervision of assistant professor Dr. AyadTaher Mohammed \\ University of Baghdad / College of Administration and Economics / Department of Business Administration
}

DOI: $10.37648 /$ ijrssh.v10i01.030

Received:18 ${ }^{\text {th }}$ October 2019; Accepted:30th November, 2019; Published:12 $2^{\text {th }}$ December, 2019

\section{INTRODUCTION}

Internal control is the most important issue as it is a concern for the accounting and financial and economic thinking, and concerns the men of law and management, where it works to protect money and support the economic resources available by continuous protection and control to achieve financial and economic growth and stability. In various countries, governments are developing instructions, regulations and laws to ensure regularity Work and prevent embezzlement and address the weakness of the accounting system or the procedures followed in the implementation in order to preserve the public funds of the State, and for this reason the State establishes an internal system of control, including work on ministries and $\mathrm{T}$ and prevent the occurrence of errors by the staff as much as possible.

Therefore, successful leaders are keen to make administrative decisions in the fields of actual work, especially when issuing decisions related to the work of internal control despite the current developments full of opportunities and threats and in light of the different forms of the departments and their diversity and different sizes, but the work of departments requires the adoption of a decision-making function where a group is available On this basis, the study was conducted in the light of internal control and its reflection in enhancing the administrative decisionmaking process in the directorate. In the first section, we will review the methodology, which relates to the problem, importance and objectives. The second section will discuss what internal control is, and the third section will be in the light of decision-making. Decision-making process.

\section{FIRST TOPIC: METHODOLOGY}

In this paper, we will review aspects of the methodology which include (problem, importance, objectives, research methodology, data collection methods, research hypothesis) through the following paragraphs:

First: the research problem

Despite the efforts exerted by the Internal Control Department in Kirkuk Water Directorate, it has not 
been concerned with the development of comprehensive internal control procedures in writing, and there is no guidance to explain the work of the Directorate to increase the efficiency of oversight operations and strengthen administrative decisions.

\section{Second: The importance of research}

The research is especially important because of the large number of works, accuracy and need to develop its view of the administrative decision-making process in Kirkuk Water Directorate to be able to cope with the accelerated changes, and find a new vision to make change an organizational work to achieve improvement in work performance and speed to meet the growing demands of the audience of beneficiaries, as well. On the theoretical importance of research, which will add to the balance in the field of internal control literature and administrative decisions .

\section{Third: Research objectives}

The research aims to identify a set of objectives related to both internal control and definition and know the types of internal control, to benefit the Directorate of Kirkuk water, as well as clarify the relationship of internal control in strengthening the decision-making process through the questionnaire in addition to determining the needs of the Directorate of internal procedures and controls to strengthen Administrative decision making process.

\section{Fourth: Research Methodology}

The study of the tagged research relied on the descriptive and analytical approach of the theoretical and field aspects to study the reality of internal control and its reflection in the decision-making process in Kirkuk Water Directorate.

\section{Fifth: Methods of data collection}

The research study was based on the scientific methods and books related to the first variable (internal control) as well as the second variable (administrative decisionmaking), in addition to the questionnaire form for the research sample (Kirkuk Water Directorate).

Sixth: Research hypothesis

\section{The research hypothesis is that:}

"There is a close correlation between internal control and its impact on management decision-making.

\section{THE SECOND TOPIC: INTERNAL CONTROL}

\section{First: the concept of internal control}

The term internal control is a synonym for internal control or internal auditing, but recently the concept of internal control has been expanded so that internal control and internal auditing have become parts of its loops. (The system of public financial protection income and spending, and any abuse of public money or negligence leads to bad results)), and is understood as a concept of financial and administrative control and has several important forms for each person assigned to oversee the implementation of a plan, whether administrative or financial (defense, 2018: 553).

The Institute of Chartered Accountants also defined the internal control as: ((the procedures carried out by the competent authorities and legally authorized to ensure the achievement of the objectives set in advance, and to ensure the integrity and legitimacy of the work done to achieve these goals and then take the necessary measures to address deviations)), The concept implies that internal control prevents mistakes or misuse of resources and protects them from loss and embezzlement (Malik, 2017: 290).

Internal control is defined as: (an internal system consisting of the organizational plan of the Unit with a division of duties and responsibilities and an accounting and reporting system, as well as all other methods and means used within the Organization to achieve its objectives). Finance and Accounting (Yahiya and Ali, 2016: 437).

Therefore, oversight is one of the main tasks of the success of the administrative process that overlaps with all other administrative functions, so it is defined as: ((complex routine procedures under the manual and does not work in overseeing the work and efficiency of staff, as it promotes the principle of preventive control and predict errors before they occur and work This is a 
management tool that can be used to organize the paths set by the organization to achieve the desired objectives and to ensure this in internal control (Abu Nasser \& Amar, 2011: 6).

\section{Second: The importance of internal control}

Internal control is an important function of management as it requires reliable information from the various activities in the organization and based on faith in modern management and the services it achieves in the area of its commitment to transactions when implemented, in addition it contributes to enhance administrative transparency and the ability to make administrative decisions where it includes A set of processes, functions and sub-activities aimed at achieving the goals and objectives of the Organization (Amar, 2017: 112). The importance of internal control can be illustrated as follows:

1. The organizational plan and all procedures aiming to test the accuracy of the accounting data in the books and accounts and the degree of reliability and to determine the integrity of the accounting treatment, in addition to the allocation of locked places for warehouses in the protection of the assets of the economic unit and the use of modern means to open and lock those stores, and the use of digital safes and risk insurance Theft, embezzlement and disasters, depending on the validity of the registration and operation of operations and requires the division of labor and audit of each process in terms of registration and the existence of an independent internal audit department as it plays a major role in this regard (Hussein, 2017: 530)

2. The extent to which the Department has succeeded in the efficient and effective use of the economic resources available to the Organization.

3. Achieving the requirements of preserving the environment in order to ensure the institution to continue the activity in addition to achieving growth and stability(Ayoub, 2014: 294).

\section{Third: Types of Internal Control}

Internal control is divided into several types according to certain criteria:

A- Censorship in terms of the time it is exercised and is divided into: - (Katie, 2018: 7)

1. Previous control: is the financial and accounting information before implementation in order to ensure that they meet the rules, principles and instructions to be observed in such transactions and this type of control is more effective in reducing the occurrence of errors and irregularities.

2. Subsequent control: The examination of financial and accounting transactions at a later date for execution. Any transaction completion and execution are audited and may be days, months or years later.

B- Censorship in terms of its performance style and is divided into: -(Yahiya and Ali, 2016: 439)

1. Comprehensive control: It is the examination of physical and accounting transactions on a continuous basis and not for a certain period, that is, oversight throughout the year and continuously without interruption.

2. Partial time control: It focuses on transactions for a certain period of time.

C- Operational Internal Control: This is an unconventional field of control. This type of internal control has arisen as a result of developments in the field of internal audit. It is defined by a comprehensive examination of the operational unit or organization as a whole to evaluate its various systems, management control and operational performance according to a specific measurement method within the management objectives. S efficiency and economic operations (return 2012: 182).

D- Control in terms of specialization and activities are divided into: (Attara, 2012: 41)

1. Oversight of administrative work: This type of control aims to optimize the use of human and material resources through the follow-up and evaluation of all the various administrative activities in the organization, including the services provided and extends to include 
different administrative levels and organizational structure and methods of work of personnel affairs and financial technical aspects.

2. Technical Control: This type of control aims at focusing the technical supervisors in various professional fields such as engineering works, production design, technical and legal.

\section{THE THIRD TOPIC: ADMINISTRATIVE DECISION MAKING PROCESS}

First: the concept of the decision-making process

Decision is an act of choice and preference whereby the manager can reach what needs to be done in the face of a particular position of the work he supervises. It is clear from the understanding that decision-making is the process of choosing a decision based on a particular behavior, methods or approaches to determine the optimal alternative (Jabouri and Hakim, 2016: 44).

The essence of management is not the nature of the prevailing relations between employees and between them and the administration, but rather the decisions issued by the administration regardless of the nature of the organization or what the behavior, and believes both (Salem, Mahmoud and Hammoudat, 2011: 31) The process of decision-making is:

((the issuance of scientific and rational decisions requires reliance on facts, data and figures and the distinction between values and facts when making decisions)), it is understood that the management problems are achieved in a scientific way, as if mathematical equations are solved by calculating their value So that is rational.

Management decision-making is defined as: "the future plan of the organization concerned to achieve a particular goal with minimal costs and the highest possible returns resulting from its implementation" The concept means that decision-making is the objective criterion for the future of the organization and has a significant impact on its profitability (Shamaa, 2010: 239).

\author{
Second: the importance of the decision-making \\ process
}

The decision-making process is very important as it has recently adopted the general theory of modern leadership as it is a process that takes place at various administrative levels in the organization and is linked to all activities and activities, which means that these levels are exposed to situations and problems must be taken to lead to the success of the new policy or any change in Existing Policy (Jubouri and the Governor, 2016: 45).

The importance of decisions and their role in achieving growth and development of the Organization has emerged as an exceptional process in the administrative areas to contribute to enable the organization to continue its administrative activities efficiently and effectively, especially that the decision depends mainly on the future and achieved its level of expectations, which complicates the tasks of management and its performance requirements in the modern era Accompanying scientific and technological developments and imposing management challenges on making traditional means of adopting personal experience and the use of error and health unable to achieve the objectives of the organization that requires sound decisions in the areas of optimal investment of human resources Available material (Muhammad, 2013: 23).

The importance that different organizations attach to the responsibility of decision-making lies in their activities within the framework of the great scientific and technological context in which human societies require the adoption of a clear scientific vision in decision-making. In line with the development and complexity experienced by different organizations, the administrative decisions today have become a useful tool and mainly reflect the extent to which the success or failure of the leadership of the organization in directing humanitarian efforts Yields of available resources(Shamaa, 2010: 240).

\section{Third: the stages of the decision-making process}

The decision-making process should be based on a series of phases, so the stages of the decision-making process can be summarized as follows: 
A- Identify the problem: It is a problem that is diagnosed as an important step in the decisionmaking process and that the wrong diagnosis results in a wrong decision, and must be careful and full knowledge of all aspects of the problem and diagnosis in terms of quality and quality and identification through the search for all the main and secondary causes of the problem In order to develop perceptions and direct efforts to solve them (Jubouri and the Governor, 2016: 46).

B- Identify the appropriate alternatives: the solutions or methods available to the administrative man to solve the problem and achieve the objectives and should carry out an adequate study to identify alternatives, and requires several things, including: (the ability to develop alternative solutions and development of solutions, especially new ones) or (reliance on extensive experiences Previous records, information and experience in the same field so that all information and aspects related to the problem can be learned) (Salem, Mahmoud, Hammoudat, 2011: 32).

C- Evaluation of alternatives: The assessment process is linked to one of the first is the extent to which the alternative is applicable in light of the objectives and resources of the organization, and the second is the ability of the alternative to solve the problem at hand, so the alternative is "logical" but not feasible or useless and requires conditions of "rationality" or "rational" The decision-maker is able to predict the results of each alternative under consideration, but because of specific information about the future, it is necessary to try to examine and determine the importance or weight, the decision-maker depends on the evaluation process through (amounts of money, hours of work, etc.) (Shamaa, 2010: 256).

D- Choosing the best alternative: The decision maker through the experience of the manager and the efficiency and strength of his personality and his ability to behave properly and psychological state as well as the circumstances surrounding the work and internal and external pressures exerted on the decision maker (Barber, 2010: 194).

E- Implementation of the decision taken: This last stage after selecting the appropriate alternative and building a certain standard, the decisionmaking process is not finished yet to see the extent of this decision on the achievement of the goal for which the decision was made, and therefore the decision must be communicated to all those involved to ensure This may also assist the Organization in making the necessary adjustments to ensure the achievement of the objective behind the decision, especially if it is different and new to previous decisions (Amine, 2010: 45).

It can be said from the above that the decision is the focus of the administrative process and revolves around all other aspects of administrative organization, and the need for the work of decisions exist in the administrative organizations, which (ie, decisions) affected by several factors, including with regard to the ocean and psychological aspects of decision-makers and the way in which the delivery The importance of decision-making, particularly with regard to clarifying the strategies and the means by which they are taken and the intended results.

\section{FOURTH TOPIC: RESULTS OF THE ANALYSIS OF THE STUDY VARIABLES IN (KIRKUK WATER DIRECTORATE)}

Through the questionnaire form distributed to the employees of Kirkuk Water Directorate, the results of the arithmetic meanings and the standard deviations related to the subject of the study (internal control and its reflection on the process of enhancing the decision-making), whether positive or negative, were presented. Measurements used in the questionnaire in addition to personal information, namely the number of males and females and scientific level, and age as shown in the following tables: 
First: Demographic information

1. Males and females: It determines the number of males and the number of females who expressed their opinion in the questionnaire form.

Table 1: Percentage distribution of males and females

\begin{tabular}{|l|l|l|}
\hline Product & the number & The ratio \\
\hline Males & 18 & $66.7 \%$ \\
\hline Females & 9 & $33.3 \%$ \\
\hline Total & 27 & $100 \%$ \\
\hline
\end{tabular}

The total number of males reached (18) and got a percentage (66.7\%), while the females totaled (9) by (33.3\%) to become the total number of (27) or by $(100 \%)$.

\begin{tabular}{|c|c|c|}
\hline Age & the number & The ratio \\
\hline $20-29$ & 4 & $14.8 \%$ \\
\hline 30-39 & 14 & $51.9 \%$ \\
\hline 40And more & 9 & $33.3 \%$ \\
\hline Total & 27 & $100 \%$ \\
\hline
\end{tabular}

2. According to age: It determines the age categories of employees in the Internal Audit Department, which ranges from (20-29) where the number reached (4), or by (14.8\%) for this age group, while the category (3039 ) reached the number (14) any $(51.9 \%)$ where this category occupied the largest percentage and this indicates that the Directorate possesses the experienced and skilled workers in the department, while the age group (40 or more) number (9), or by (33.3\%) This percentage indicates that the Directorate has heads and officials Units and divisions as shown in the following table (2):

\section{Table (2) Percentage Distribution by Age Groups}

3. According to the educational qualification: It reflects the academic achievement where the number of holders of secondary certificate (8) or 29.6\%, while the bachelor holders (12) or $44.4 \%$ and the diploma holders (4) any (14.8\%), which indicates that the Department needs a cadre with graduate degrees has reached the number of master's degree holders (3), or by $(11.1 \%)$, which is the total in the department, and must be 
attracting those with higher degrees, which helps to strengthen the process of taking Administrative decisions and then improve the mechanism of internal control work as branch managers agency management.

Table (3) Percentage Distribution by Educational Qualification

\begin{tabular}{|r|r|r|l|}
\hline Certificate & the number & The ratio \\
\hline Secondary & $\mathbf{8}$ & $29.6 \%$ \\
\hline Baccalaureate & 12 & $44.4 \%$ \\
\hline diploma & 4 & $14.8 \%$ \\
\hline Majesty & 3 & $11.1 \%$ \\
\hline Total & & 27 & $100 \%$ \\
\hline
\end{tabular}

Second: Presentation of the results of the first variable (internal control)

the frequency distribution, arithmetic mean and standard deviation on the dimensions of internal audit (efficiency, training, independence), as paragraphs (113) were questions related to measuring dimensions, and achieved a total average of (2.487) and is inclined to rise, and these The result indicates that the Directorate is moderately concerned with the dimensions of internal control in anticipation of the negative reactions of the employees, especially after the decision-making process, and that the overall standard deviation was 1.379 , respectively. They reflected a tendency It is larger to the second dimension, where the general arithmetic mean (2.812) is superior to the general arithmetic mean of the first and third dimension as the mean arithmetic (2.505) (2.145), and this variable was measured in three dimensions are:

First Dimension Efficiency: This dimension achieved a general arithmetic mean of (2.505), which is lower than the other general media, and a general standard deviation of (1.287), which reflects the degree of inconsistency in the responses of respondents either at the level of paragraphs (1-4) ranged around values Arithmetic mean among the highest value achieved by paragraph (3) (Upgrading the staff of the Internal Control Division subject to the standards of expertise and efficiency in the Directorate of Kirkuk water) amounted to (2.81), while the standard deviation
(1.44). It also showed the lowest arithmetic mean achieved by paragraph (2) (the Directorate follows appropriate and appropriate methods for the selection of qualified employees in the IOD and selected on the basis of competence) (1.96), and an acceptable dispersion of the answer with a standard deviation of (1.28).

The second dimension Training: This dimension has achieved a general arithmetic mean above the arithmetic mean of the first dimension tends to rise by (2.812) and acceptable dispersion in the answer as the standard deviation (1.326), and at the level of paragraphs (5-9) has achieved paragraph (6) (is Involve the trainees in the preparation and drawing of training plans and programs in the Directorate (the highest mean is (3.33), and the acceptable dispersion in the answer as the standard deviation (1.28), and the lowest mean of this dimension achieved by paragraph (8)) The directorate was (1.96) and acceptable dispersion in the answer, where the standard deviation reached (1.28), respectively.

The third dimension of independence: This dimension achieved a general arithmetic mean of (2.145), which is lower than the hypothetical mean and tends to rise, which confirms the state of harmony in the responses of the sample between internal control and decision-making, where the standard deviation (1.525), but at the level Paragraphs (10-13), the highest arithmetic mean of paragraph (10) (the Internal Control Division is administratively linked to the top 
management of the direct and direct) as it reached (2.81) and acceptable dispersion in the answer as the standard deviation (1.59), while achieved paragraph (12) (IOD has powers commensurate with its responsibilities and duties) a Nie compromise mathematically, amounting to (1.48) and diffusely acceptable answer, as it reached its standard deviation (1.28).

Third: the results of the second variable (decisionmaking) according to iterations, arithmetic mean and standard deviations

The frequency distribution, arithmetic mean and standard deviation around the decision-making paragraphs . Paragraphs (14-28) represented the questions related to measuring decision-making. It achieved a total average of (2.552) which is greater than the total mean of the first variable (internal control). This is a natural result which reflects the reality of the Directorate's interest in making decisions, and an acceptable dispersion in the answer, where the total standard deviation reached (1.324), respectively, and at the level of paragraphs has occurred paragraph (28) (the problem that hinders the work of the Directorate is clearly diagnosed, enabling it to Making the right administrative decision (b) The lowest percentage of decision-making paragraphs (27) provides the IAOD reports with sufficient information to diagnose administrative and financial problems impeding the achievement of Objectives of the Directorate.), At the lowest value of (2.00), with an acceptable dispersion of the answer (1.44), and it turns out that the Directorate is keen to take decisions in a moderate manner and the adoption of modern methods in the Department of Internal Control and objective models appropriate to the nature of work moderately according to the results of the arithmetic mean.

\section{Fourth: Testing hypotheses}

\section{Test the correlation hypothesis can be verified through:}

The resultsshowed that there is a significant correlation between internal control and administrative decision-making process. The value of the correlation was $(\mathbf{0 . 6 7 8})$. It states (there is a close correlation between internal control and administrative decision-making).

Table (4): The correlation coefficient between internal control and administrative decision making

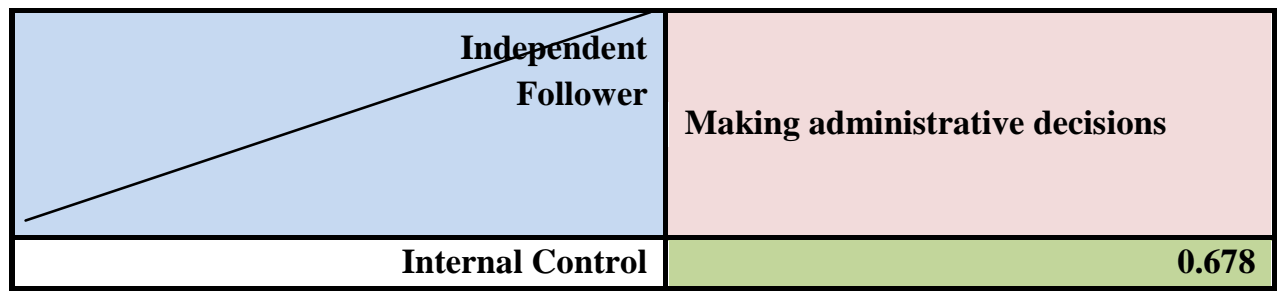

2. Test the impact relationship between internal control and the process of administrative decision-making in the following table:

Table (5) shows that the coefficients of (13) indicate that there is an impact, but very strong and moral, which indicates that the dimensions of internal control have a significant role in influencing the decision-making process in the Kirkuk Water Directorate, and this result provides sufficient support To accept the research hypothesis, which states that there is a correlation between internal control and administrative decision-making affects the positive reinforcement of the decisions of the Directorate. 
Table (5) Transactions of the Effect of Internal Control on Administrative Decision Making Process

\begin{tabular}{|r|r|r|r|r|r|}
\hline \multicolumn{9}{|c|}{ Making administrative decisions } & \\
\hline Moral & R2 & F & B & A & Follower \\
\hline 0.000 & 0437 & 21.2 & 0755 & 0678 & Independent \\
\hline
\end{tabular}

The scope of the internal audit function includes, in particular, the following: Periodic inspection of departments, including control and risk management systems in the Company, at appropriate intervals to determine whether the administrative, accounting and control functions and functions are effectively performed, in accordance with the Company's policies, procedures and instructions Complies with company objectives and best management practices including the following: Methods and techniques used to maintain and protect the company's assets, including information assets, from the risk of theft, damage, destruction, misuse, neglect, inefficiency, and business practices Improper disclosure or corruption.

The extent to which the financial and operational information prepared within the Directorate can be relied upon, the means used to identify, measure, classify and report on such information, existing systems to ensure compliance with policies, plans and procedures that have an impact on the Directorate; Which were examined by the results of the audit conducted by the Internal Audit Department and the opinions and recommendations reached with a view to verifying that the necessary measures have been taken to address the identified weaknesses and to evaluate the plans and actions taken by the relevant departments. Relationship to address the observations and recommendations, which include the audit report and in the case of insufficient actions taken are discussed this with staff officials to ensure the adequacy of the actions taken.

\section{THE FIFTH TOPIC: CONCLUSIONS AND RECOMMENDATIONS}

\section{First: Conclusions}

1. Internal auditing is an important means for economic units to pay attention to, because of its significant role in the protection and preservation of property and follow-up activities and tasks of the economic unit.

2. Internal audit is an important means through which errors are detected, fraud and monitoring the integrity of the operations and documents of the unit.

3. In the presence of a sound system of internal control, this would achieve the objectives of the economic unit to protect its property and add value to it.

\section{Second: Recommendations}

1. The need to pay attention to internal audit of internal control because of the great importance of protecting and maintaining its assets.

2. Giving a greater role to the internal control in order to detect all errors and fraud and follow up all the operations of the (Kirkuk Water Directorate).

3. Work to provide a sound internal control system that would achieve the objectives of the Directorate in the process of making administrative decisions.

\section{SOURCES:}

1. Defense, Susan Mire Mahaloul (2018), (The role of internal control bodies in evaluating the performance of service institutions), Mstel Master Thesis, Journal of the Faculty of Basic Education 
for Educational and Human Sciences, University of Babylon, No. (38), Babylon.

2. Kati, Ali Hassan (2018), (Internal control system and its role in the government accounting system), Journal of the University of Qadisiyah, Baghdad.

3. Al-Hussein, Murtaza Mohammed Shane, and Ibrahim Abdul-Musa Al-Sabawi (2017), (Employing internal control components to enhance the quality of external audit), Journal of the University of Babylon, Volume (25), No. (4), Babylon.

4. Malik, Yasser Sahib (2017), (The basic elements of internal control and its impact on the effectiveness of internal control and audit / applied study in a sample of public universities), Journal of the University of Kufa, Volume (2), Issue (44), Kufa.

5. Al-Jubouri, Adnan Aziz Jiad, and the Governor, Ali Abdullah (2016), (the intermediate role of organizational values in the relationship between decision-making process and institutional performance), Journal of the Islamic College University, Vol. 3, No. (51), Baghdad.

6. Yahiya, Abbas Hammed, NasifJassim Mohammed (2016), (Procedures of internal control and internal control in the Technical Education Authority), Journal of Economic and Administrative Sciences, Volume (19), Issue (71), Baghdad.

7. Ayoub, A. Pan Hani (2014), (The role of internal audit in the evaluation of environmental performance) Journal of Baghdad College of Economic Sciences University, No. 42, Baghdad.

8. Mohammed, Faisal Younis (2013), (Strategies for management decision-making), Journal of Educational and Psychological Research, vol (2), No. (36), Baghdad.

9. Odeh, Ahmad Nofal, Al-Baghdadi, Salah Sahib Shaker (2012), (The efficiency and effectiveness of internal control in evaluating the performance of government institutions), Journal of the University College of Heritage, Vol. 3, No. (20), Baghdad.

10. Attara, Fouad Sharif (2012), (Internal management control in government institutions and their role in improving work performance from the viewpoint of the Office of Financial and Administrative
Control), Master Thesis, Al-Quds University, Palestine.

11. Salem, Mohammed Zakir, and Iyad Ali Mahmoud, and ThabitIhsanHammoudat (2011), (making administrative decisions by the heads of departments and rapporteurs), Journal of Sports Culture quarterly scientific refereed, Volume (3), Issue (1), Baghdad.

12. Al-Hallaq, Mohammad Ali (2010), (The Effectiveness of Administrative Decision Making Process among Heads of Departments and Administrative Divisions in the Education Directorate in Damascus Governorate), TishreenUniversity Journal for Research and Scientific Studies, Vol. 32, No. 2, Syria.

13. Shamaa, Khalil Mohammed Hassan, and KhadirKazemHammoud (2010), (Theory of the Organization) Dar Al-Masirah for Publishing and Distribution, Fourth Edition, Jordan.

14. Abu Nasser\& Amar(2011).(Impact of Communication and Information on the Internal Control Environment in Palestinian Universities),Technology, Al-Azhar University, Gaza, Palestine.

15. Amar Tarek,(2017),(International Journal of Digital Publication Technology), Technology, AlAzhar University, Gaza, Palestine. 